\title{
Interaction between Output Efficiency and Environmental Efficiency: Evidence from the Textile Industry in Jiangsu Province, China
}

Lei Jiang ${ }^{\mathrm{a}}$, Henk Folmer ${ }^{\mathrm{b}, \mathrm{a}}$, Maoliang Bu $\mathrm{Bu}^{\mathrm{c}, \mathrm{d}, \mathrm{e}}$

a. Department of Economic Geography, Faculty of Spatial Sciences, University of Groningen, Landleven 1, 9747 AD, Groningen, The Netherlands

b. Department of Agricultural Economics, College of Economics and Management, Northwest A\&F University, Yangling, Shaanxi, China

c. School of Business, Nanjing University, Nanjing, Jiangsu, China

d. Hopkins-Nanjing Center, Nanjing, Jiangsu, China

e. Chair of China Business and Economics, Würzburg University, Würzburg, Germany

\begin{abstract}
Environmental efficiency improvement has played a crucial role in the theory and practice of stimulating clean production. This paper analyzes the interaction between environmental efficiency and output efficiency, particularly whether they reinforce each other or compete with each other, on the basis of a data set of 137 firms in the textile industry in China's Jiangsu province. In the first stage, generalized data envelopment analysis is applied to calculate efficiency measures of energy, waste water, waste gas, soot, and output efficiency taking capital, labor, water, and energy as inputs, industrial output value as desirable output, and waste water discharges, waste gas and soot emissions as undesirable outputs. In the second stage analysis, a structural equation model with latent variables is applied to analyze the interaction between the latent variable environmental efficiency, measured by the four observed environmental indicators, and output efficiency, taking also into account the endogenous variable profit. The main outcomes of the structural equation model are the following. Firstly, environmental efficiency negatively impacts on profit while profit positively impacts on environmental efficiency. In a similar vein, output efficiency is found to depress profit while profit increases output efficiency. Thirdly, environmental efficiency has a positive impact on output efficiency while there is no effect of output efficiency on environmental efficiency. Fourthly, taxes impair a firm's output efficiency. From the findings it follows that a swap of general taxes for an energy tax is likely to improve both output efficiency and energy efficiency. The latter outcome implies a win-win situation which will facilitate the further implementation and adoption of environmental policy. Finally, the paper illustrates the applicability of structural equation modeling in efficiency analysis
\end{abstract}

Keywords: Energy efficiency; Output efficiency; Environmental efficiency; Data envelopment analysis (DEA); Structural equation model (SEM); Jiangsu Province

\section{Introduction}

Environmental efficiency improvement has played a crucial role in the theory and practice of stimulating clean production. Nevertheless, the determinants and impacts of environmental 
efficiency are not fully understood yet. This applies in particular to the relationship between environmental efficiency and output efficiency. There are two possible effects of environmental efficiency, notably energy efficiency, on output efficiency. First, a positive effect in that an environmentally friendly/energy efficient firm has lower energy costs which, ceteris paribus, improves its output efficiency. On the other hand, improving environmental efficiency implies opportunity costs in that the resources used to improve environmental efficiency could have been used to improve output efficiency. Furthermore, not only may environmental efficiency impact on output efficiency, but also vice versa: output efficiency may impact on environmental efficiency. Again, there are two possible effects. First, a positive effect in that output efficient firms have more resources to improve environmental efficiency than output inefficient firms, ceteris paribus. Secondly, a negative effect in that improving output efficiency absorbs resources to improve environmental efficiency.

Environmental efficiency, notably energy efficiency, has played a crucial role in China. Its unprecedented economic growth has been accompanied by a dramatic increase in energy consumption. It has risen more than sixfold over the past 35 years, from 571 million tons standard coal equivalent (SCE) in 1978 to 3750 in 2013 (NBS, 2014). China is now the world's largest energy consumer (Liao et al., 2007; Wang et al., 2012; Bian et al., 2013). In 2013, it accounted for $22.4 \%$ of global primary energy consumption (BP, 2014). Specifically, it consumed approximately $12.12 \%$ of global oil, nearly $5 \%$ of global natural gas, about $50 \%$ of global coal, and $24 \%$ of global hydro power. Besides, it has become one of the largest energy producers in the world (Herrerias et al., 2013). For example, in 2013 China's coal production accounted for nearly half of the world's total (BP, 2014).

China's energy consumption has led to two major challenges, viz. energy shortage and environmental degradation (Song et al., 2011; Meng et al., 2013; Lin and Ouyang, 2014). Regarding the first challenge, China has been suffering from a rapidly widening energy gap for more than two decades. In 2013, there was a deficiency of 350 million tons SCE (NBS, 2014), accounting for $9.3 \%$ of China's energy consumption of 3750 million tons SCE. Consequently, China has expanded its energy imports, particularly of oil. In 2013, imports of oil accounted for nearly $70 \%$ of China's total oil consumption (NBS, 2014).

Regarding the second challenge, environmental degradation in China has been worsening due to emissions of various pollutants caused by fossil fuel combustion (Yong and Oberheitmann, 2008; Wang et al., 2012). In 2012, $\mathrm{SO}_{2}$ emissions totaled 21.2 million tons, $\mathrm{NO}_{\mathrm{x}}$ emissions 23.4 million tons, smoke and dust 12.4 million tons, and $\mathrm{CO}_{2}$ emissions 9.9 billion tons (NBS, 2013; Netherlands Environmental Assessment Agency, 2013). $\mathrm{SO}_{\mathrm{x}}$ and $\mathrm{NO}_{\mathrm{x}}$, which are the main causes of acid rain, have affected about 300 cities in China (Zhang et al., 2011). Economic losses caused by fossil fuel combustion based pollution accounted for 3.9\% of China's GDP in 2008 (Li et al., 2013). Coal combustion is the main source. Specifically, $90 \%$ of $\mathrm{SO}_{\mathrm{x}}, 67 \%$ of $\mathrm{NO}_{\mathrm{x}}$ and $70 \%$ of total $\mathrm{CO}_{2}$ emissions in China result from coal combustion (Fang and Zeng, 2007).

Energy efficiency improvement has played a crucial role in addressing both energy shortage and environmental degradation in China (Tanaka, 2008; Andrews-Speed, 2009). Its improvement has been regarded as a top priority by the Chinese central government for years. In the $11^{\text {th }}$ Five-Year Plan (2006-2010), the Chinese government for the first time launched a nationwide 
campaign aimed at improving energy efficiency. To this end, the Plan specified targets for each provincial government. In a similar vein, municipal governments were assigned targets by their provincial governments.

Adequate measures of energy efficiency can be obtained by means of stochastic frontier analysis (SFA) and data envelopment analysis (DEA) (see Hu and Wang, 2006; Chien and Hu, 2007; Martínez, 2011). SFA is a parametric approach that requires functional specifications. Furthermore, it takes only one output into consideration. DEA, proposed by Charnes et al. (1978), on the other hand, is a non-parametric (optimization) approach that can deal with a system of multiple outputs and inputs ( $\mathrm{Wu}, 2014)$. Moreover, it does not require functional specifications between the inputs and the outputs (Seiford and Thrall, 1990; Shi et al., 2010; Wu, 2014). Another advantage is that it only requires information on the physical quantities of inputs and outputs (Abbott, 2006). Consequently, it has gained great popularity in measuring energy efficiency (Zhou et al., 2014). For example, Wei et al. (2009) used DEA to measure energy efficiency of 29 Chinese provinces for the period 1997-2006. The author found that the eastern region had the highest energy efficiency score, the western region the lowest while the central region had an in-between position. Another application is Martínez (2011) who applied DEA to measure energy efficiency development in non energy-intensive sectors in Germany and Colombia during the period 1998-2005. The author found that the average energy efficiency scores were similar in both countries. Thirdly, Blomberg et al. (2012) evaluated electricity efficiency of more than 30 pulp and paper mills for the period 1995, 2000 and 2005 by means of DEA. They observed that the electricity efficiency gap among the mills was relatively stable over time.

Conventional DEA models proceed on the basis of the assumption that inputs are minimized and economic output is maximized in the production process (Scheel, 2001; Jahanshahloo et al., 2005). This assumption ignores the fact that production not only produces desirable output, but also undesirable outputs, particularly emissions (Färe and Grosskopf, 2004; Färe et al., 2005; Zhou et al., 2007; Liu et al., 2010; Wang et al., 2012; Wang et al., 2013; Pérez-Calderón et al., 2011, Wu, 2014; Chen et al., 2015). If undesirable outputs, e.g. pollutants, are ignored in (energy) efficiency evaluation, a distorted picture of (energy) efficiency may result. Both desirable (goods) and undesirable outputs (bads) should be considered in efficiency analysis (Seiford and Zhu, 2002; Rashidi et al., 2014; Song et al., 2012). DEA that takes both goods and bads into account is denoted here as generalized DEA (GDEA).

The basic notion to incorporate both goods and bads (e.g. pollutants) in the DEA framework originates from Pittman (1983)'s seminal work. In recent years, it has gained popularity in energy efficiency analysis. For example, Sözen et al. (2010) in their generalized efficiency analysis of 15 thermal power plants in Turkey, took thermal efficiency, operational time, and fuel cost as inputs, electricity as desirable output, and $\mathrm{CO}_{2}, \mathrm{SO}_{2}, \mathrm{~N}_{2} \mathrm{O}, \mathrm{CH} 4, \mathrm{CO}, \mathrm{NO}_{\mathrm{x}}$, and non-methane volatile organic compounds (NMVOC) emissions as undesirable outputs. They found that there was a large efficiency gap across the 15 thermal power plants. Another application is Sueyoshi and Goto (2014) who used three inputs, viz. assets, employees and energy, in their generalized efficiency analysis of 31 Japanese chemical and pharmaceutical firms. They took sales as desirable output, and greenhouse gas emissions and waste discharges as undesirable outputs. They found that the pharmaceutical firms outperformed the chemical firms. 
There are also some Chinese studies that took undesirable outputs into account. For example, Shi et al. (2010) measured industrial energy efficiency of 28 provinces for the period 2000-2006, taking assets, labor, and energy as inputs, industrial added value as desirable output, and waste gas as undesirable output. They found that the eastern region had the highest average energy efficiency score, followed by the central and western regions. Wang et al. (2012) used capital stock, labor, coal, oil, and natural gas as inputs, gross provincial product as desirable output, and $\mathrm{CO}_{2}$ and $\mathrm{SO}_{2}$ as undesirable outputs to measure energy efficiency of China's 30 provinces for the period 2000-2009. In line with Shi et al (2010), the eastern provinces were found to have the highest energy efficiency scores, followed by the central and western provinces. Wang et al. (2013) and $\mathrm{Li}$ et al. (2013) reported energy efficiency scores for 29 Chinese provinces during the period of 2000-2008 and 1991-2001. They took gross provincial product as desirable output, capital stock, labor and energy as inputs, $\mathrm{CO}_{2}$ emissions and $\mathrm{SO}_{2}$ emissions as two undesirable outputs, while the latter also considered waste water, waste gas and solid waste as undesirable outputs. Again, the eastern provinces were found to have the highest energy efficiency score, followed by the central provinces and the western provinces.

Few studies have been conducted at firm level in China. An exception is He et al. (2013), who evaluated energy efficiency of 50 large iron and steel enterprises taking three undesirable outputs, viz. waste gas, waste water and solid waste, into consideration. They found that the average energy efficiency was only 0.611 . We have not been able to find empirical efficiency studies for small and medium-sized firms in China in the literature which is probably due to data limitations.

The existing literature has merely paid attention to the calculation of efficiency and ignored the possible interaction between desirable output efficiency and environmental efficiency. The present paper intends to fill this gap. It analyzes the interaction between environmental efficiency and output efficiency based on a data set of 137 small and medium-sized textile firms in China's Jiangsu Province in 2009. First output efficiency and environmental efficiency indicators are estimated by means of GDEA taking capital, labor, water, and energy as inputs. Next, a structural equation model (SEM) with output efficiency and environmental efficiency as interacting latent endogenous variables will be estimated.

The structure of the paper is as follows. Section 2 briefly summarizes the GDEA and SEM. Section 3 describes the study area and data sources while section 4 presents the empirical results. Section 5 concludes and presents policy recommendations.

\section{Methods}

Generalized data envelopment analysis (GDEA) is introduced in subsection 2.1. In section 4, it will be applied to calculate the efficient levels of the inputs which in their turn are used to calculate indices of energy efficiency $(E E F)$, waste water efficiency $(W W E F)$, waste gas efficiency $(W G E F)$, soot efficiency $(S T E F)$, and output efficiency $(O u t E F)$ for each firm. The output of GDEA (the four environmental measures) are input into the SEM which will be applied to analyze the interaction between output efficiency and environmental efficiency, measured by the above four environmental indices. The SEM is summarized in subsection 2.2.

\subsection{Generalized DEA (GDEA)}


Consider a production system with $\mathrm{n}$ decision making units (DMUs). The production has inputs, desirable (good) outputs and undesirable (bad) outputs, represented by three vectors: $x \in R^{m}$ (inputs), $y^{g} \in R^{q_{1}}$ (desirable or good output), and $y^{b} \in R^{q_{2}}$ (undesirable or bad output), respectively. Furthermore, let $\mathrm{m}, \mathrm{q}_{1}$ and $\mathrm{q}_{2}$ represent the number of inputs, desirable outputs and undesirable outputs, respectively. The input matrix $X$, the desirable output matrix $Y^{g}$, and the undesirable output matrix $Y^{b}$ are defined as: $X=\left[x_{1}, \ldots, x_{n}\right] \in R^{m \times n}, \quad Y^{g}=\left[y_{1}^{g}, \ldots, y_{n}^{g}\right] \in R^{q_{1} \times n}$, $Y^{b}=\left[y_{1}^{b}, \ldots, y_{n}^{b}\right] \in R^{q_{2} \times n}$. It is assumed that all inputs and outputs are non-negative.

The production possibility set $(P)$ is defined as:

$$
P=\left\{\left(x, y^{g}, y^{b}\right) \mid \mathbf{x} \geq X \lambda, \mathbf{y}^{g} \leq Y^{g} \lambda, \mathbf{y}^{b} \leq Y^{b} \lambda, \lambda \geq 0\right\}
$$

where $\lambda$ is the intensity vector.

As an introduction to GDEA, the calculation of the efficiency of DMU at $\left(x_{0}, y_{0}\right)$, denoted $\operatorname{MNU}\left(x_{0}, y_{0}\right)$ with only one (good) output is first considered. ${ }^{1}$ The slack-based measure (SBM) approach first proposed by Tone $(1997,2001)$ is adopted, which is formulated as the following minimization program ${ }^{2}$ :

$$
\min \rho=\frac{1-\frac{1}{m} \sum_{i=1}^{m} \frac{s_{i}^{-}}{x_{i 0}}}{1+\frac{1}{q} \sum_{r=1}^{q} \frac{s_{r}^{+}}{y_{r 0}^{g}}}
$$

$$
\begin{aligned}
& \text { Subject to } \quad \begin{array}{l}
x_{0}=X \boldsymbol{\lambda}+s^{-} \\
y_{0}=Y \boldsymbol{\lambda}-s^{+} \\
s^{-} \geq 0, s^{+} \geq 0, \lambda \geq 0
\end{array}
\end{aligned}
$$

where vectors $s^{-}$and $s^{+}$are the slack variables representing excesses input and output shortage, respectively. The value of $\rho$ is the efficiency score at $\left(x_{0}, y_{0}\right)$.

\footnotetext{
${ }^{1}$ To facilitate the linkage to the DEA literature, the general notation, including vector notation, is applied.

${ }^{2}$ An alternative approach was developed by Ebrahimnejad and Tavana (2014). The SBM approach is adopted here since the slack variables are used to calculate efficiency measures (see below).
} 
To take undesirable outputs into account, system (2)-(5) can be modified to evaluate $\operatorname{DMU}\left(x_{0}\right.$, $\left.y_{0}^{g}, y_{0}^{b}\right)$ as follows (Li et al., 2014):

$$
\rho=\min \frac{1-\frac{1}{m} \sum_{i=1}^{m} \frac{s_{i}^{-}}{x_{i 0}}}{1+\frac{1}{q_{1}+q_{2}}\left(\sum_{r=1}^{q_{1}} \frac{s_{r}^{g}}{y_{r 0}^{g}}+\sum_{r=1}^{q_{2}} \frac{s_{r}^{b}}{y_{r 0}^{b}}\right)}
$$

$$
\begin{aligned}
& \text { Subject to } \begin{aligned}
& x_{0}=X \boldsymbol{\lambda}+\boldsymbol{s}^{-} \\
& y_{0}^{g}=Y^{g} \boldsymbol{\lambda}-\boldsymbol{s}^{g} \\
& y_{0}^{b}=Y^{b} \boldsymbol{\lambda}+\boldsymbol{s}^{b} \\
& \boldsymbol{s}^{-} \geq 0, \boldsymbol{s}^{g} \geq 0, \boldsymbol{s}^{b} \geq 0, \lambda \geq 0
\end{aligned}
\end{aligned}
$$

where the vector $s^{b}$ refers to excesses in undesirable outputs and the vector $s^{g}$ denotes shortages in desirable outputs. $\rho$ is called the DMU's generalized efficiency $(\mathrm{G} E F)$ score at $\operatorname{DMU}\left(x_{0}, y_{0}^{g}, y_{0}^{b}\right)$. It satisfies $0 \leq \rho \leq 1$.

System (6)-(10) is a nonlinear program that can be transformed into a linear program (LP) by means of the Charnes-Cooper transformation as follows (Charnes and Cooper, 1962; Li et al., 2013; Chang et al., 2013; Li et al., 2014). The transformation is as follows. First, following Charnes and Cooper (1962), a scalar variable $t(t>0)$ is included into system (6)-(10) that multiplies both the denominator and the numerator of (6), and thus does not change $\rho$. Furthermore, the denominator is made equal to 1 by adjusting $t$, and, next, it is specified as a constraint ((12) below). The objective then is minimization of the numerator. System (6)-(10) now reads (Tone, 2001):

$$
\tau=\min t-\frac{1}{m} \sum_{i=1}^{m} \frac{t s_{i}^{-}}{x_{i o}}
$$

$$
\begin{aligned}
& \text { Subject to } \quad \begin{aligned}
& 1= t+\frac{1}{q_{1}+q_{2}}\left(\sum_{r=1}^{q_{1}} \frac{t s_{r}^{g}}{y_{r o}^{g}}+\sum_{r=1}^{q_{2}} \frac{t s_{r}^{b}}{y_{r o}^{b}}\right) \\
& x_{0}=X \boldsymbol{\lambda}+\boldsymbol{s}^{-} \\
& y_{0}^{g}=Y^{g} \lambda-\boldsymbol{s}^{g} \\
& y_{0}^{b}=Y^{b} \lambda+\boldsymbol{s}^{b} \\
& \boldsymbol{s}^{-} \geq 0, \boldsymbol{s}^{g} \geq 0, \boldsymbol{s}^{b} \geq 0, \lambda \geq 0
\end{aligned}
\end{aligned}
$$


System (11)-(16) contains the nonlinear term ts. It can be transformed into a linear program by defining $S^{-}=t s^{-}, S^{g}=t s^{g}, S^{b}=t s^{b}$ and $\Lambda=t \lambda$. Accordingly, system (11)-(16) becomes the following linear program (Tone, 2001):

$$
\tau=\min t-\frac{1}{m} \sum_{i=1}^{m} \frac{S_{i}^{-}}{x_{i o}}
$$

Subject to

$$
\begin{aligned}
& 1=t+\frac{1}{q_{1}+q_{2}}\left(\sum_{r=1}^{q_{1}} \frac{S_{r}^{g}}{y_{r o}^{g}}+\sum_{r=1}^{q_{2}} \frac{S_{r}^{b}}{y_{r o}^{b}}\right) \\
& x_{0} t=X \boldsymbol{\Lambda}+\boldsymbol{S}^{-} \\
& y_{0}^{g} t=Y^{g} \boldsymbol{\Lambda}-\boldsymbol{S}^{g} \\
& y_{0}^{b} t=Y^{b} \boldsymbol{\Lambda}+\boldsymbol{S}^{b} \\
& \boldsymbol{S}^{-} \geq 0, \boldsymbol{S}^{g} \geq 0, \boldsymbol{S}^{b} \geq 0, \boldsymbol{\Lambda} \geq 0, t \geq 0
\end{aligned}
$$

Let $\left(\tau^{*}, t^{*}, \Lambda^{*}, \boldsymbol{S}^{-*}, \boldsymbol{S}^{z^{*}}, \boldsymbol{S}^{b^{*}}\right)$ be the optimal solution of the linear program. Then the optimal solution of the original program (2)-(5) is

$$
\rho^{*}=\tau^{*}, \lambda^{*}=\Lambda^{*} / t^{*}, s^{-^{*}}=\boldsymbol{S}^{\boldsymbol{L}^{*}} / t^{*}, s^{g^{*}}=\boldsymbol{S}^{g} / t^{*}, s^{b^{*}}=\boldsymbol{S}^{b^{*}} / t^{*}
$$

In the present study, there are four inputs, viz. capital, labor, water, and energy; one desirable output, i.e. industrial output; and three undesirable outputs, viz. waste water discharges, waste gas emissions, and soot emissions. Note that raw materials are also important inputs. However, they are not explicitly included in the DEA since they are merged with capital in the database. Using slack variables, energy efficiency $(E E F)$, waste water efficiency $(W W E F)$, waste gas efficiency $(W G E F)$, soot efficiency $(S T E F)$, and output efficiency $(O u t E F)$ measures for each firm can be derived as follows.

The slack variable for energy input is excess energy input. Hence, EEF measures how far away a firm is from the energy efficient frontier (Hu and Wang, 2006; Wei et al. 2009). It is defined as:

$$
E E F=\frac{A E-\text { Excess } E}{A E}
$$

where $A E$ is actual energy input and Excess $E$ excess energy input. $A E$-Excess $E$ is the target energy input that represents the best, i.e. the practical minimum, level of energy input. Actual energy input is a firm's observed energy input. It is always larger than or equal to the target energy input. $E E F$ thus is restricted to the interval $(0,1]$.

The slack variable of pollutant $\mathrm{k}$ ( $\mathrm{k}$ denotes waste water, waste gas or soot in this study) is excess emission of pollutant k. Similar to (24), EnvEF is the ratio of the target emission to actual 
emission (Chang et al., 2013; Tao and Zhang, 2013). For pollutant $k$ it reads:

$$
E n v E F_{k}=\frac{A E M_{k}-E_{x c e s s} E M_{k}}{A E M_{k}}
$$

where $A E M_{k}$ is the actual emission level of pollutant $\mathrm{k}$ and ExcessEM $k$ excess emission level of pollutant k. $A E M_{k}$-ExcessEM $M_{k}$ is the target emission of pollutant $\mathrm{k}$ that represents the best, practical minimum level of pollutant k. EnvEF $F_{k}$ is restricted to the interval $(0,1]$. Based on $(25), W W E F$, $W G E F$, and $S T E F$ are derived.

The slack of industrial output represents shortage in desirable output. The target output level is the sum of actual output plus (minimum) shortage in output (Shortout). OutEF is thus defined as (Gómez-Calvet et al., 2014):

$$
\text { OutEF }=\frac{A O}{A O+\text { Shortout }}
$$

where $A O$ is actual output level. $A O+$ Shortout is the target output, i.e. the best, practical maximum level of output. OutEF is restricted to the interval $(0,1]$.

\subsection{Structural equation model (SEM)}

SEM was introduced by Jöreskog \& Sörbom (1977) and developed by inter alia Bollen (1989), Jöreskog \& Sörbom (1993), Bollen (1998), Byrne (2013). Typical for SEM is that it is able to handle latent and observed variables simultaneously within one model framework. A latent variable (theoretical construct) refers to a phenomenon that is supposed to exist but cannot be observed directly. However, it can be measured by means of observed variables (Oud and Fomer (2008) and the references therein). Examples of latent variables in economics are welfare, propensity to consume, expectation.

A SEM consists of two types of sub-models. First, the measurement models for the endogenous and exogenous latent variables:

$$
\begin{aligned}
& y=\Lambda_{y} \eta+\varepsilon \\
& x=\Lambda_{x} \xi+\delta
\end{aligned}
$$

where $y$ is $\mathrm{p} \times 1$ vector of endogenous observed variables, $x$ a $\mathrm{q} \times 1$ vector of exogenous observed variables, $\eta$ an $\mathrm{m} \times 1$ vector of latent endogenous variables, and $\xi$ an $\mathrm{n} \times 1$ vector of latent exogenous variables. $\Lambda_{y}$ and $\Lambda_{x}$ are $\mathrm{p} \times \mathrm{m}$ and $\mathrm{q} \times \mathrm{n}$ matrices of loadings (coefficients) for $\eta$ and $\xi$, respectively. $\varepsilon$ and $\delta$ are $\mathrm{p} \times 1$ and $\mathrm{q} \times 1$ vectors of the measurement errors, respectively. Note that the two measurement models can be combined into a single measurement model (see inter alia Oud and Folmer, 2008).

The second sub-model is, the structural model that specifies the relationships among the latent variables. It reads:

$$
\eta=B \eta+\Gamma \xi+\zeta
$$

where $B$ is an $\mathrm{m} \times \mathrm{n}$ matrix with $\beta_{i j}$ representing the relationships among the latent endogenous variables; $\Gamma$ an $\mathrm{m} \times \mathrm{n}$ matrix giving the effects of the exogenous latent variables on the endogenous 
latent variables and $\zeta$ an $\mathrm{m}$ vector of disturbances. For an overview of identification, estimation, testing and model modification, see Jöreskog and Sörbom (2001). Note that it is possible to include an observed variable in the measurement models and the structural model by taking it identical to its corresponding latent variable (loading equal to 1 and measurement error equal to 0 ). Furthermore, it is possible to include intercepts in the measurement models and in the structural model (Jöreskog \& Sörbom, 2001). However, in this paper they are omitted because standardized or beta coefficients are estimated to facilitate comparisons of the effects.

In the structural model, output efficiency $(O u t E F)$ is an endogenous latent variable that is identical to observed efficiency (as estimated by GDEA) whereas the endogenous latent variable environmental efficiency $(E n v E F)$ is measured by the four indicators $E E F, W W E F, W G E F$, and $S T E F$, obtained from equations (24) and (25). Furthermore, a third endogenous latent variable, Profit, is included in the structural model that is taken identical to observed Profit. It is hypothesized that Profit has positive impacts on either or both $O u t E F$ and $E n v E F$, since a firm with higher profits has more resources to improve efficiency than one with lower profits, ceteris paribus. A reverse relationship, from $E n v E F$ and $O u t E F$ to Profit, is also hypothesized. A priori, the signs of the impacts are ambiguous. Either or both may be positive because efficiency implies lower production costs. On the other hand, however, efficiency improvement requires outlays on equipment and training which lower profits, ceteris paribus. As outlined in the Introduction, direct interactions between $E n v E F$ and $O u t E F$ are also hypothesized.

The data set analyzed contains several exogenous variables (controls) that are assumed to impact on the endogenous variables, i.e. the ratio of capital to labor (Clratio), age (Age), taxes (Taxes), size (Size), liabilities (Liabilities) and sales (Sales). Based on theoretical considerations or intuition, the controls are assumed to impact on several of the endogenous variables. Particularly, for Clratio, which is the vintage of capital, a high value indicates new, high tech capital and a low value old-fashioned capital (Metcalf, 2008; Wang, 2011; Wu, 2012). Clratio thus is expected to directly affect Profit, EnvEF and OutEF. Particularly, a positive impact on environmental efficiency is likely, since new vintage capital tends to be more environmentally friendly, notably more energy efficient (Wu, 2012). Liabilities, defined as the total amout of all financial obligations and Taxes, defined as taxes and surcharge paid for main operations and made up of business tax, urban construction and maintenance tax, resource use tax, and land appreciation tax, imply additional costs and thus are assumed to reduce profits (Ang et al., 2000; Miller, 2011; Xu et al., 2011; Razak et al., 2011; Sun and Wang, 2014). Both variables are also expected to directly and negatively affect both efficiency variables. ${ }^{3}$ Size, on the other hand, is likely to have positive impacts on all three endogenous variables because of the ability of large firms to exploit economies of scale, to hire skilled workers and managers, and to adopt advanced technologies (Zheng et al, 2003; Xia and Cheng, 2010; Wang and Hao, 2012; Sun and Wang, 2014; Lin and Long, 2015). In a similar vein,

\footnotetext{
3 Note that Taxes do not necessarily hamper Efficiency via investments because investments depend on many factors, including expected sales, the level of taxation, depreciation rules, dividend policy, investment tax-shield, firm size, debt service, etc. The objective of this paper is not analysis of the conditions under which Taxes hamper investments or not. Such an analysis would be far beyond the scope of the paper. Moreover, the data is not available. We merely estimate the impact of Taxes on efficiency. Also note that Liabilities do not necessarily reduce profit and resources. The impact dependes on a variety of circumstances. As in the case of Taxes, we do not analyze the conditions under which Liabilities hamper Profit or not. We merely estimate the impact of Liabilities on Profit.
} 
Sales is assumed to positively affect Profit and the efficiency variables. ${ }^{4}$ Finally, since it goes along with knowledge accumulation and learning by doing, Age is likely to positively affect Profit and $O u t E F$. Note that there are also variables that impact on the endogenous variables but are constant for all the firms in the data set. For example, norms and legislation impact on EnvEF. Such variables are constant because the affected firms belong to the same jurisdiction (Jiangsu). ${ }^{5}$

Estimation of simultaneous equations models of which all equations contain virtually all controls is infeasible because of identification problems. However, there is little evidence to a priori exclude impacts of the controls on the three endogenous variables. As a way out, a heuristic approach is adopted which involves estimation of several models that differ in terms of restrictions (i.e. zero constraints) on the coefficients in the $\Gamma$ component of the structural model. Out of the estimated models, the final model is chosen based on theoretical plausibility, significance of the estimated coefficients and overall goodness of fit. Note that the final model thus obtained is preliminary, especially regarding the relationships between the controls and the endogenous variables since it has not been estimated and tested in previous studies and thus it is based on the present data set only.

In terms of equation (27)-(28), the SEM efficiency model outlined above reads as follows:

Measurement model of the endogenous latent variables:

$$
\left[\begin{array}{c}
E E F \\
W W E F \\
W G E F \\
S T E F \\
\text { OutEF } \\
\text { Profit }
\end{array}\right]=\left[\begin{array}{ccc}
1 & 0 & 0 \\
\lambda_{21}^{y} & 0 & 0 \\
\lambda_{31}^{y} & 0 & 0 \\
\lambda_{41}^{y} & 0 & 0 \\
0 & 1 & 0 \\
0 & 0 & 1
\end{array}\right]\left[\begin{array}{c}
E n v E F \\
\text { OutEF } \\
\text { Profit }
\end{array}\right]+\left[\begin{array}{c}
\varepsilon_{1} \\
\varepsilon_{2} \\
\varepsilon_{3} \\
\varepsilon_{4} \\
0 \\
0
\end{array}\right]
$$

Measurement model of the exogenous variables:

\footnotetext{
${ }^{4}$ Note that there could be a cycle from Sales to Profit to Efficiency and back to Sales, e.g. via price reduction. However, the allocation of the returns to efficiency improvement is multifaceted. The returns could be used for expansion, to raise wages and so on. The interesting research question of the allocation of efficiency gains is beyond the scope of the paper, inter alia, because of identification problems. Therefore, we defined Sales as an exogenous variable.

${ }^{5}$ Note that environmental regulations may have different impacts depending, for instance, on location and size of the firm but also on local circumstances such as corruption. Unfortunately, there is no information in the data set on these variables, except for Size which is included in the model as exogenous variable. Therefore, we can merely assume that omitted variables like location and corruption (captured by the error term) are not, or only slightly, correlated with the explanatory variables. The plausibility of the estimated coefficients lends support to this assumption.
} 


$$
\left[\begin{array}{c}
\text { Clratio } \\
\text { Age } \\
\text { Taxes } \\
\text { Size } \\
\text { Liabilities } \\
\text { Sales }
\end{array}\right]=\left[\begin{array}{lllll}
1 & 0 & 0 & 0 & 0 \\
0 & 1 & 0 & 0 & 0 \\
0 & 0 & 1 & 0 & 0 \\
0 & 0 & 0 & 1 & 0 \\
0 & 0 & 0 & 0 & 1
\end{array}\right]\left[\begin{array}{c}
\text { Clratio } \\
\text { Age } \\
\text { Taxes } \\
\text { Size } \\
\text { Liabilities } \\
\text { Sales }
\end{array}\right]
$$

Structural model:

$$
\begin{aligned}
{\left[\begin{array}{c}
\text { EnvEF } \\
\text { OutEF } \\
\text { Profit }
\end{array}\right] } & =\left[\begin{array}{ccc}
0 & 0 & \beta_{1,3} \\
\beta_{2,1} & 0 & \beta_{2,3} \\
\beta_{3,1} & \beta_{3,2} & 0
\end{array}\right]\left[\begin{array}{c}
\text { EnvEF } \\
\text { OutEF } \\
\text { Profit }
\end{array}\right] \\
& +\left[\begin{array}{cccccc}
\gamma_{1,1} & 0 & 0 & 0 & 0 & 0 \\
0 & \gamma_{1,2} & \gamma_{2,3} & \gamma_{2,4} & 0 & 0 \\
0 & 0 & 0 & 0 & \gamma_{3,5} & \gamma_{3,6}
\end{array}\right]\left[\begin{array}{c}
\text { Clratio } \\
\text { Age } \\
\text { Taxes } \\
\text { Size } \\
\text { Liabilities } \\
\text { Sales }
\end{array}\right]+\left[\begin{array}{l}
\varsigma_{1} \\
\varsigma_{2} \\
\varsigma_{3}
\end{array}\right]
\end{aligned}
$$

Note that to render the model identified, the coefficient of $E E F$ is fixed at 1 in equation (29) thus assigning a measurement scale to the unobserved latent variable $E n v E F$. Furthermore, in equation (30) the latent variables are equal to their observed indicators. As a result, the error terms are fixed at 0 .

\section{Study area and data sources}

The data analyzed relate to China's Jiangsu province (hereafter Jiangsu) in 2009. Jiangsu had a population of 79 million (in 2011) that accounted for about $6 \%$ of China's total. It is located in the Yangtze River Delta and has an area of 102600 square kilometers, about $1.1 \%$ of the entire nation's (Long and Ng, 2001; Jiangsu Statistical Yearbook 2012).

Jiangsu is one of the economically most developed provinces and has a high economic growth rate. Its Gross Provincial Product (GPP) has been growing from 25 billion Yuan in 1978 to 4911 billion Yuan in 2011, with an average annual nominal growth rate of $17.4 \%$ and a real annual growth rate of $12.3 \%$. Jiangsu has played an important role in China's economic development (Zhang and Huang, 2012). Its Gross Provincial Product (GPP) accounted for almost $10 \%$ of China's GDP in 2011 (NBS, 2012). Among 31 Chinese provinces (excluding Taiwan, Hongkong, Macau), its GPP ranked second, only behind Guangdong province. However, its rapid economic growth has been accompanied by substantial energy consumption.

Jiangsu has been suffering from energy shortages for years. In 2000 it produced 20 million tons SCE only, but consumed 86 million tons, resulting in a deficiency of 66 million tons. In 2011 Jiangsu's energy consumption of 276 million tons SCE even more exceeded its energy supply of 26 million tons SCE. The ratio of energy production to energy consumption sharply declined from $23 \%$ in 2000 to less than $10 \%$ in 2011 , indicating a rapidly widening energy gap during the past decade. The main reason is that Jiangsu lacks energy resources. Specifically, it is endowed with only $0.5 \%$ of China's total coal reserves, $1.05 \%$ of its oil reserves and $0.06 \%$ of its natural gas 
reserves. It also lacks hydro power because it is plain. It is relatively rich in wind power, though. Jiangsu thus heavily depends on imports of energy from energy-rich provinces.

Jiangsu heavily depends on the use of coal (more than 70\% in 2011) which has been the main cause of environmental degradation. In 2011, $\mathrm{SO}_{2}$ emissions totaled 1.1 million tons, $\mathrm{NO}_{\mathrm{x}}$ emissions 1.5 million tons, and smoke and dust 0.5 million tons. These pollutants have serously deteriorated Jiangsu's environment.

Energy efficiency improvement has played a major role in reducing energy consumption and emissions in Jiangsu. Energy intensity has substantially decreased, from 3.9 tons SCE per 10,000 Yuan in 1990 to 1.3 in 2010 (in 1990 constant prices). However, it still lags behind developed countries (Hong et al., 2013) indicating that Jiangsu has a huge potential to improve its energy efficiency. In the $11^{\text {th }}$ Five-Year Plan (2006-2010), a specific target of improving energy efficiency by $20 \%$ was assigned to Jiangsu. By the end of 2010, it had successfully reduced energy consumption per unit of GPP by $20.5 \%$ (Duan and $\mathrm{Hu}, 2014$ ). No targets were set for the main pollutants, however.

The data set includes 137 firms, classified into 3 manufacturing sectors at 2-digit level, based on the "Classification and code standard of national economy industry" released by the National Bureau of Statistics of China (source: http://www.stats.gov.cn/tjsj/tibz/hyflbz/). The 3 sectors, viz. "manufacturing of textile", "manufacturing of wearing apparel and accessories", and "manufacturing of leather, fur, feather and related products and footwear" are grouped into one single group, viz. textile, according to similarities between products. Data is available for 2009 only. Data for capital, labor, and industrial output value is obtained from the Chinese Industrial Enterprises Database which is not publicly available. ${ }^{6}$ Data for water use, energy consumption, waste water discharges, waste gas emissions, and soot emissions is obtained from the Environmental Protection Department of Jiangsu. Table 1 presents the definitions, units of measurement, and descriptive statistics (mean, standard deviation (SD), minimum (Min) and maximum (Max)) of the input variables, and of the desirable and undesirable output variables of the GDEA. Note that due to data limitations the only energy source considered is coal. So, the energy efficiency indicator below is in fact a "coal indicator". This limitation affects the environmental only marginally because coal is by far the most important energy source in the Jiangsu textile industry.

\section{Table 1 about here}

Data for the controls in the SEM is from the Chinese Industrial Enterprises Database. Table 2 presents their definitions, units of measurement, and descriptive statistics.

\section{Table 2 about here}

\section{Empirical results}

Table 3 presents descriptive statistics of the output of the GDEA (equations (17)-(23), i.e. the efficiency indices $G E F, E E F, W W E F, W G E F, S T E F$, and $O u t E F$. The table shows that generalized

\footnotetext{
${ }^{6}$ The data was made available to the third co-author for the present study.
} 
efficiency has the lowest mean among all efficiency measures. This is because it is a multi-factor efficiency measure which combines inputs and output leading to the low generalized efficiency score. It indicates substantial potential to save inputs or to improve output.

The means of the single factor efficiency measures $E E F, W W E F, W G E F$ and $S T E F$ range from 0.2896 to 0.3874 and are much lower than that of OutEF. Note also that the means of the environmental efficiency indicators $E E F, W G E F$ and $S T E F$ are very close which is due to the fact that they are all highly related to coal combustion.

\section{Table 3 here}

The SEM is estimated by means of the software package LISREL 8 (Jöreskog and Sörbom, 2001). The results are presented in Tables 4-6. The Initial Model in Table 4 includes all relevant variables in the data set (briefly discussed in Section 2). However, the variable Age turned out to be highly insignificant in all models and was deleted from the analysis. The resulting model is the Final Model. Table 4 presents overall-goodness-of-fit measures of the Initial (including Age) and of the Final Model (without $A g e$ ): the $\chi^{2} / \mathrm{df}$, the root mean square error of approximation (RMSEA), the goodness of fit index (GFI), the adjusted goodness of fit index (AGFI), the comparative fit index (CFI), and the normed fit index (NFI). (Note that it is possible to apply a $\chi^{2}$ based test. However, the test is highly sensitive to deviation from normality and hampered by small sample size (Jöreskog and Sörbom (2001), Hox and Bechger, (1998)). Under those conditions the fit measures $\chi^{2} / \mathrm{df}$ and RMSEA are more appropriate.) From Table 4 it follows that the goodness of fit statistics of both the Initial and Final Models meet their critical values, although the $\chi^{2} / \mathrm{df}$ and the RMSEA of the former are slightly better than those of the latter. On the basis of these results the Final Model is now discussed.

\section{Table 4 here}

The modification indices of the structural model presented in Table 5 give hints about incorrectly fixed or constrained parameters. More precisely, a modification index is the predicted decrease in $\chi^{2}$, if a single fixed parameter or equality constrained is relaxed and the model is re-estimated (Jöreskog and Sörbom, 2001). As a rule of thumb, a modification index larger than 7 is an indication of an incorrectly fixed or constrained parameter. Table 5 shows that none of the fixed parameters exceeds the critical value which supports the parameter configuration (i.e. the fixed (at 0 ) and free, estimated parameters).

\section{Table 5 here}

Tables 6 presents the estimated measurement models. Before discussing the results, note that the estimated coefficients are standardized (beta) coefficients. They are directly comparable since a beta coefficient represents the standard deviation change in an endogenous variable due to a standard deviation change in an explanatory variable (Wooldridge, 2012). Note that standardization also affects the coefficients of the indicators $E E F, O u t E F$, and Profit that originally were fixed at 1 .

Table 6 shows that all factor loadings of the indicators of the latent variable EnvEF are highly 
significant and that their reliabilities $\left(R^{2}\right)$ are larger than the minimum level of 0.20 recommended by Jöreskog \& Sörbom (2001). Hence, EnvEF is measured well. Note also that the loadings of the indicators are virtually equal.

\section{Table 6 here}

Table 7 here

Figure 1 here

The structural model is presented in Table 7 and Figure 1. Table 7 shows that all the coefficients in the structural model are significant at $10 \%$. Moreover, the R-squared of the three equations are quite high. Below the two efficiency sub-models are first discussed, next the profit sub-model.

Profit has a positive impact on EnvEF, indicating that profit induces EnvEF. Clratio on the other hand negatively and significantly impacts on $E n v E F$. A possible explanation is that the textile industry still is labor-intensive rather than capital and energy-intensive. A high capital labor ratio might imply excess investment in capital and equipment resulting in higher than optimal energy use which impairs $E n v E F$. Note that the estimated impact of $O u t E F$ on $E n v E F$ was virtually zero and highly insignificant. It was therefore fixed at 0 .

From the output efficiency sub-model it follows that EnvEF has a positive impact on OutEF, indicating that, ceteris paribus, an environmentally friendly firm tends to save costs via reduction of inputs, notably energy. The positive impact of Profit on OutEF implies that a high profit firm can save on costs e.g. via installment of efficient capital thus improving OutEF. Taxes negatively impact on OutEF indicating that a heavy tax burden impairs a firm's OutEF. Size has a positive impact on OutEF implying that a large firm tends to exploit economies of scale, which benefits OutEF.

The profit sub-model shows that EnvEF and OutEF negatively impact on Profit indicating that both kinds of efficiency improvement absorb resources at the expense of Profit. Liabilities also have a negative impact on Profit. Sales on the other hand positively impact on Profit, indicating that a firm with high turnover tends to have high profits.

\section{Table 8 here}

Table 8 presents the total effects of all explanatory variables on EnvEF, OutEF and Profit. The total effect of an explanatory variable on an endogenous variable is the sum of its direct and indirect effects on that variable (Jöreskog and Sörbom, 2001). The former is given by the coefficient in the structural model (Table 7). The latter is the effect of the variable on the endogenous variable via intervening endogenous variables. Note that an endogenous variable can have an effect on itself via reciprocal or circular paths via other endogenous variables. The table shows that OutEF (-0.47), Liabilities (-0.38) and Size (-0.23) have significant and negative total effects on EnvEF while EnvEF also has a negative effect on itself via Profit. Clratio has a marginally significant, negative total effect (-0.09) on EnvEF. There is no direct effect of Taxes on EnvEF. However, its negative effect on OutEF (-0.26) has a negative impact on Profit (-1.47) which in its turn 
has a positive impact on EnvEF (1.18). The effect of Taxes on OutEF along this path is positive: 0.45. This effect is reduced by -0.33 which is the sum of the effects of the loop among EnvEF and Profit. Thus, its total effect on EnvEF amounts to 0.12. Sales (0.76) has a significant, positive total effect on EnvEF via Profit, although it has no direct effect. The significant total effects of Size (-0.23) and Liabilities (-0.38) also arise from indirect effects, i.e. via the intervening endogenous variables OutEF and Profit.

The variables with significant, positive total effects on OutEF are EnvEF (0.09), Profit (0.28), Size (0.28) and Sales (0.67). Note that there is no direct effect of Sales on OutEF. However, it has a positive total effect via Profit. Taxes (-0.15) and Liabilities (-0.33) have negative total effects on OutEF while it also has a negative effect on itself via Profit. The negative total effect of Liabilities (-0.33) comes from the indirect effect via Profit.

The variables with negative total effects on Profit are EnvEF (-0.51), OutEF (-0.40), Liabilities (-0.32) and Size (-0.19) while Profit (-0.73) also have a negative effect on itself via EnvEF and OutEF. The negative total effects of the first two variables are smaller than their direct effects because of indirect effects (the negative relationship between $E n v E F$ and OutEF leading to a positive impact on Profit). Clratio has no direct effect on Profit. However, it has a significant and positive total effect on Profit (0.32) via EnvEF. Taxes have no direct effect on Profit, either. However, their positive total effect (0.10) on Profit arises from the indirect effect via OutEF. In a similar vein, Size (-0.19) indirectly impacts on Profit via OutEF, although it has no direct effect, either. The total effect of Sales (0.64) on Profit is smaller than its direct effect because Profit has a negative effect on the efficiency variables which feedback on Profit.

\section{Conclusion and policy recommendations}

The main purpose of this paper was the analysis of the interaction between environmental efficiency and output efficiency, particularly, whether they reinforce each other or compete with each other. For this purpose, a data set of 137 firms in the textile industry in China's Jiangsu province was analyzed. As a first step, efficiency measures for energy $(E E F)$, waste water $(W W E F)$, waste gas $(W G E F)$, soot $(S T E F)$, and output $(O u t E F)$ were calculated by means of Generalized DEA (GDEA) taking capital, labor, water, and energy as inputs, industrial output value as desirable output, and waste water discharges, waste gas emissions, and soot emissions as undesirable outputs. In the second-stage analysis, the interaction between the two efficiency measures was analyzed by way of a structural equation model with latent variables (SEM). The input into the SEM was obtained from the GDEA. Environmental efficiency $(E n v E F)$ was measured by the four environmental indicators, and output efficiency $(O u t E F)$ was taken identical to observed OutEF. Profit was also included in the SEM as an endogenous variable.

The main findings of the analysis are the following. Environmental efficiency has a negative impact on profit while profit has a positive impact on environmental efficiency. A similar relationship holds for output efficiency and profit: output efficiency reduces profit while profit induces output efficiency. The rationale is that efficiency improvement requires resources which depresses profit. Furthermore, environmental efficiency positively affects output efficiency but there is no reverse effect. Regarding the control variables, the capital labor ratio negatively and significantly affects environmental efficiency, taxes output efficiency and liabilities profit. Firm 
size on the other hand has a positive impact on output efficiency and sales on profit.

The finding that environmental efficiency induces output efficiency has implications for environmental policy, at least in sectors like the textile sector in Jiangsu. First, the results indicate that although environmental policy aimed at improving environmental efficiency, particularly energy efficiency, depresses profit, it stimulates output efficiency. This is an indication for policymakers to continue the development and implementation of environmental policy aimed at improving environmental and energy efficiency. The rationale is that such a policy is not only desirable from an environmental and energy policy point of view, but also from a broader economic perspective because rising production costs have increasingly started hampering exports (Singh and Mahmood, 2014). This is in line with IEA (2014) which shows that investment in energy efficiency may have several benefits to firms. Evidently, it directly reduces energy demand and associated costs. Moreover, it may facilitate the achievement of some objectives, for example, boosting industrial productivity. Further stimulation of environmental and energy efficiency also fits into the national and $11^{\text {th }}$ Five Year Plan (2006-2010) and its follow up of the $12^{\text {th }}$ Five Year Plan (2011-2015). It follows that investment in energy efficiency leads to a win-win situation which may facilitate the adoption of such environmental policy by firms. A possible energy efficiency stimulating policy is a tax swap of general taxes for an energy tax. As shown in the analysis taxes impair a firm's output efficiency. An energy tax on the other hand is a stimulus to reduce energy use. A tax swap is thus likely to improve both output efficiency and energy efficiency.

The analysis presented in this study relates to a small sector in one province for one year only. Further analysis of other sectors in other regions and over longer time spans is needed. For that purpose the methodology presented in this paper consisting of generalized DEA and structural equation modeling with latent variables, is promising. Besides, this study relates to China. However, environmental degradation, energy shortage and energy efficiency are also major issues in other developing countries like India, Pakistan, Bangladesh, Indonesia and several African and Latin American countries. The analyses could be readily applied in other (developing) countries.

Acknowlegements: We are grateful for very helpful suggestions by three anonymous reviewers and our editor. The third author acknowledges the support of the Alexander von Humboldt Foundation.

\section{References:}

Abbott, M., 2006. The productivity and efficiency of the Australian electricity supply industry. Energy Economics, 28(4), 444-454.

Andrews-Speed, P., 2009. China's ongoing energy efficiency drive: Origins, progress and prospects. Energy Policy, 37(4), 1331-1344.

Ang, J. S., Cole, R. A., \& Lin, J. W., 2000. Agency costs and ownership structure. The Journal of Finance, 55(1), 81-106.

BP., 2014. Statistical Review of World Energy 2014.

Bian, Y., He, P., \& Xu, H., 2013. Estimation of potential energy saving and carbon dioxide emission reduction in China based on an extended non-radial DEA approach. Energy Policy, 63, 962-971.

Blomberg, J., Henriksson, E., \& Lundmark, R., 2012. Energy efficiency and policy in Swedish pulp and paper mills: 
A data envelopment analysis approach. Energy Policy, 42, 569-579.

Bollen, K. A., 1989. Structural equations with latent variables. John Wiley \& Sons.

Bollen, K. A., 1998. Structural equation models. In: Armitage P. Colton T., Eds.), Encyclopedia of Biostatistics. John Wiley \& Sons Inc., New York.

Byrne, B. M., 2013. Structural equation modeling with LISREL, PRELIS, and SIMPLIS: Basic concepts, applications, and programming. Psychology Press.

Chang, Y. T., Zhang, N., Danao, D., \& Zhang, N., 2013. Environmental efficiency analysis of transportation system in China: A non-radial DEA approach. Energy Policy, 58, 277-283.

Charnes, A., \& Cooper, W. W., 1962. Programming with linear fractional functionals. Naval Research Logistics Quarterly, 9(3-4), 181-186.

Charnes, A., Cooper, W. W., \& Rhodes, E., 1978. Measuring the efficiency of decision making units. European Journal of Operational Research, 2(6), 429-444.

Chen, J., Song, M., \& Xu, L. 2015. Evaluation of environmental efficiency in China using data envelopment analysis. Ecological Indicators, 52, 577-583.

Chien, T., \& Hu, J. L., 2007. Renewable energy and macroeconomic efficiency of OECD and non-OECD economies. Energy Policy, 35(7), 3606-3615.

Duan, H., \& Hu, Q., 2014. Local officials' concerns of climate change issues in China: A case from Jiangsu. Journal of Cleaner Production, 64, 545-551.

Ebrahimnejad, A., \& Tavana, M. 2014. An interactive MOLP method for identifying target units in output-oriented DEA models: The NATO enlargement problem. Measurement, 52, 124-134.

Fang, Y., \& Zeng, Y., 2007. Balancing energy and environment: The effect and perspective of management instruments in China. Energy, 32(12), 2247-2261.

Färe, R., \& Grosskopf, S., 2004. Modeling undesirable factors in efficiency evaluation: Comment. European Journal of Operational Research, 157(1), 242-245.

Färe, R., Grosskopf, S., Noh, D. W., \& Weber, W., 2005. Characteristics of a polluting technology: Theory and practice. Journal of Econometrics, 126(2), 469-492.

Oud, J. H., \& Folmer, H., 2008. A structural equation approach to models with spatial dependence. Geographical Analysis, 40(2), 152-166.

Gomez-Calvet, R., Conesa, D., Gómez-Calvet, A. R., \& Tortosa-Ausina, E., 2013. Energy efficiency in the European Union: What can be learned from the joint application of directional distance functions and slacks-based measures?. Applied Energy, 132, 137-154.

He, F., Zhang, Q., Lei, J., Fu, W., \& Xu, X., 2013. Energy efficiency and productivity change of China's iron and steel industry: Accounting for undesirable outputs. Energy Policy, 54, 204-213.

Herrerias, M. J., Joyeux, R., \& Girardin, E., 2013. Short-and long-run causality between energy consumption and economic growth: Evidence across regions in China. Applied Energy, 112, 1483-1492.

Hong, L., Lund, H., Mathiesen, B. V., \& Möller, B., 2013. 2050 pathway to an active renewable energy scenario for Jiangsu province. Energy Policy, 53, 267-278.

Hu, J. L., \& Wang, S. C., 2006. Total-factor energy efficiency of regions in China. Energy Policy, 34(17), 3206-3217.

Hooper, D., Coughlan, J., \& Mullen, M. R., 2008. Structural equation modelling: Guidelines for determining model fit. Electronic Journal of Business Research Methods, 6(1), 53-60.

Hox, J. J., \& Bechger, T. M., 1998. An introduction to structural equation modelling. Family Science Review, 11, 354-373.

IEA., 2014. Capturing the Multiple Benefits of Energy Efficiency. 
IMF., 2011. World Economic Outlook 2010.

IMF., 2014a. World Economic Outlook: Recovery Strengthens, Remains Uneven.

IMF., 2014b. World Economic Outlook: Legacies, Clouds, Uncertainties.

Jahanshahloo, G. R., Lotfi, F. H., Shoja, N., Tohidi, G., \& Razavyan, S., 2005. Undesirable inputs and outputs in DEA models. Applied Mathematics and Computation, 169(2), 917-925.

Jiangsu Statistics Bureau., 2012. Jiangsu Statistical Yearbook 2012.

Jöreskog, K. G., 1977. Factor analysis by least squares and maximum likelihood methods. in: Enslein, K., Ralston, A., Wilf, H.S., Eds.), Statistical Methods for Digital Computers. John Wiley \& Sons Inc., New York.

Jöreskog, K. G., \& Sörbom, D., 1993. LISREL 8: Structural equation modeling with the SIMPLIS command language. Scientific Software International.

Jöreskog, K. G., \& Sörbom, D., 2001. LISREL 8 user's reference guide. Scientific Software International.

Li, H., \& Shi, J. F., 2014. Energy efficiency analysis on Chinese industrial sectors: An improved Super-SBM model with undesirable outputs. Journal of Cleaner Production, 65, 97-107.

Li, H., Fang, K., Yang, W., Wang, D., \& Hong, X., 2013. Regional environmental efficiency evaluation in China: Analysis based on the Super-SBM model with undesirable outputs. Mathematical and Computer Modelling, 58(5), 1018-1031.

Liao, H., Fan, Y., \& Wei, Y. M., 2007. What induced China's energy intensity to fluctuate: 1997-2006?. Energy Policy, 35(9), 4640-4649.

Lin, B., \& Long, H., 2015. A stochastic frontier analysis of energy efficiency of China's chemical industry. Journal of Cleaner Production, 87, 235-244.

Lin, B., \& Ouyang, X., 2014. Energy demand in China: Comparison of characteristics between the US and China in rapid urbanization stage. Energy Conversion and Management, 79, 128-139.

Liu, W. B., Meng, W., Li, X. X., \& Zhang, D. Q., 2010. DEA models with undesirable inputs and outputs. Annals of Operations Research, 173(1), 177-194.

Long, G., \& Ng, M. K., 2001. The political economy of intra-provincial disparities in post-reform China: A case study of Jiangsu province. Geoforum, 32(2), 215-234.

Martínez, C. I. P., 2011. Energy efficiency development in German and Colombian non-energy-intensive sectors: A non-parametric analysis. Energy Efficiency, 4(1), 115-131.

Meng, F. Y., Fan, L. W., Zhou, P., \& Zhou, D. Q., 2013. Measuring environmental performance in China's industrial sectors with non-radial DEA. Mathematical and Computer Modelling, 58(5), 1047-1056.

Metcalf, G. E., 2008. An empirical analysis of energy intensity and its determinants at the state level. The Energy Journal, 1-26.

Miller, S. E., 2011. Governance mechanisms as moderators of agency costs in a pre-SOX environment. Journal of Business \& Economics Research, 7(10), 15-32.

National Bereau of Statistics of China., 2012. China Statiscial Yearbook 2012.

National Bereau of Statistics of China., 2013. China Statiscial Yearbook 2013.

National Bereau of Statistics of China., 2014. China Statiscial Yearbook 2014.

Netherlands Environmental Assessment Agency., 2013. Trends in global $\mathrm{CO}_{2}$ emissions: 2013 report.

Pittman, R. W., 1983. Multilateral productivity comparisons with undesirable outputs. The Economic Journal, 883-891.

Pérez-Calderón, E., Milanés-Montero, P., Meseguer-Santamaría, M. L., Mondéjar-Jiménez, J., Gazquez-Abad, J. C., Jimenez-Guerrero, J. F., ... \& Bartha, I., 2011. Eco-efficiency: effects on economic and financial performance. Evidences from Dow Jones Sustainability Europe Index. Environmental Engineering and Management Journal, 10(12), 1801-1808. 
Rashidi, K., Shabani, A., \& Saen, R. F., 2014. Using data envelopment analysis for estimating energy saving and undesirable output abatement: a case study in the Organization for Economic Co-Operation and Development (OECD) countries. Journal of Cleaner Production (In press).

Razak, N. H. A., Ahmad, R., \& Joher, H. A., 2011. Does government linked companies (GLCs) perform better than Non-GLCs? Evidence from Malaysian listed companies. Journal of Applied Finance \& Banking, 1(1), 213-240.

Scheel, H., 2001. Undesirable outputs in efficiency valuations. European Journal of Operational Research, 132(2), 400-410.

Seiford, L. M., \& Thrall, R. M., 1990. Recent developments in DEA: The mathematical programming approach to frontier analysis. Journal of Econometrics, 46(1), 7-38.

Seiford, L. M., \& Zhu, J., 2002. Modeling undesirable factors in efficiency evaluation. European Journal of Operational Research, 142(1), 16-20.

Shi, G. M., Bi, J., \& Wang, J. N., 2010. Chinese regional industrial energy efficiency evaluation based on a DEA model of fixing non-energy inputs. Energy Policy, 38(10), 6172-6179.

Singh, H., \& Mahmood, R. (2014). Combined effect of competitive and manufacturing strategies on export performance of small and medium enterprises in Malaysia. Global Journal of Management and Business Research, 14(1), 92-100.

Song, M., An, Q., Zhang, W., Wang, Z., \& Wu, J., 2012. Environmental efficiency evaluation based on data envelopment analysis: A review. Renewable and Sustainable Energy Reviews, 16(7), 4465-4469.

Song, M., Wang, S., Yu, H., Yang, L., \& Wu, J., 2011. To reduce energy consumption and to maintain rapid economic growth: Analysis of the condition in China based on expended IPAT model. Renewable and Sustainable Energy Reviews, 15(9), 5129-5134.

Sueyoshi, T., \& Goto, M., 2014. DEA radial measurement for environmental assessment: A comparative study between Japanese chemical and pharmaceutical firms. Applied Energy, 115, 502-513.

Sun, X. H., \& Wang, Y., 2014. R\&D investment and total factor productivity: The PSM analysis based on industrial firm-level data of China. Science Research Management, 35(11), 92-99.

Sözen, A., Alp, İ., \& Özdemir, A., 2010. Assessment of operational and environmental performance of the thermal power plants in Turkey by using data envelopment analysis. Energy Policy, 38(10), 6194-6203.

Tanaka, K., 2008. Assessment of energy efficiency performance measures in industry and their application for policy. Energy Policy, 36(8), 2887-2902.

Tao, Y., \& Zhang, S., 2013. Environmental efficiency of electric power industry in the Yangtze River Delta. Mathematical and Computer Modelling, 58(5), 927-935.

Tone, K., 1997. Several algorithms to determine multipliers for use in cone-ratio envelopment approaches to efficiency evaluations in DEA. In Computational Approaches to Economic Problems. Springer US.

Tone, K., 2001. A slacks-based measure of efficiency in data envelopment analysis. European Journal of Operational Research, 130(3), 498-509.

Wang, H., 2011. Research on the efficiency of production of large and medium sized industrial enterprises in Anhui province. Science Technology and Industry, 11(1), 49-55, 88.

Wang, K., Wei, Y. M., \& Zhang, X., 2012. A comparative analysis of China's regional energy and emission performance: Which is the better way to deal with undesirable outputs?. Energy Policy, 46, 574-584.

Wang, K., Yu, S., \& Zhang, W., 2013. China's regional energy and environmental efficiency: A DEA window analysis based dynamic evaluation. Mathematical and Computer Modelling, 58(5), 1117-1127.

Wang, M. W., \& Hao, Q. J., 2012. Start-up size, initial productivity and enterprises' survival and development. Economic Management Journal, (7), 144-153. 
Wei, C., Ni, J., \& Shen, M., 2009. Empirical analysis of provincial energy efficiency in China. China \& World Economy, 17(5), 88-103.

Wooldridge, J., 2012. Introductory Econometrics: A Modern Approach. Cengage Learning.

Wu, J., An, Q., Yao, X., \& Wang, B., 2014. Environmental efficiency evaluation of industry in China based on a new fixed sum undesirable output data envelopment analysis. Journal of Cleaner Production, 74, 96-104.

Wu, Y., 2012. Energy intensity and its determinants in China's regional economies. Energy Policy, 41, 703-711.

Xia, Y. L., \& Cheng, L., 2010. Research on the spillover effects of fdi on the technical efficiency of China's industrial enterprises The quantitative analysis of Chinese industrial firms from 2002 to 2006. Journal of China Industrial Economics, (7),55-65.

Xu, W., Zeng, Y., \& Zhang, J., 2011. Tax enforcement as a corporate governance mechanism: Empirical evidence from China. Corporate Governance: An International Review, 19(1), 25-40.

Yong, L., \& Oberheitmann, A., 2008. Factors enabling the decoupling of China's energy-related emissions from its economic growth. ASIEN, 106, 7-23.

Zhang, M., \& Huang, X. J., 2012. Effects of industrial restructuring on carbon reduction: An analysis of Jiangsu Province, China. Energy, 44(1), 515-526.

Zhang, M., \& Wang, W., 2012. Using an energy flow chart to analyze Jiangsu Province's energy balance. Renewable Energy, 39(1), 307-312.

Zhang, N., Lior, N., \& Jin, H., 2011. The energy situation and its sustainable development strategy in China. Energy, 36(6), 3639-3649.

Zheng, J., Liu, X., \& Bigsten, A., 2003. Efficiency, technical progress, and best practice in Chinese state enterprises (1980-1994). Journal of Comparative Economics, 31(1), 134-152.

Zhou, G., Chung, W., \& Zhang, Y., 2014. Measuring energy efficiency performance of China's transport sector: A data envelopment analysis approach. Expert Systems with Applications, 41(2), 709-722.

Zhou, P., Poh, K. L., \& Ang, B. W., 2007. A non-radial DEA approach to measuring environmental performance. European Journal of Operational Research, 178(1), 1-9. 


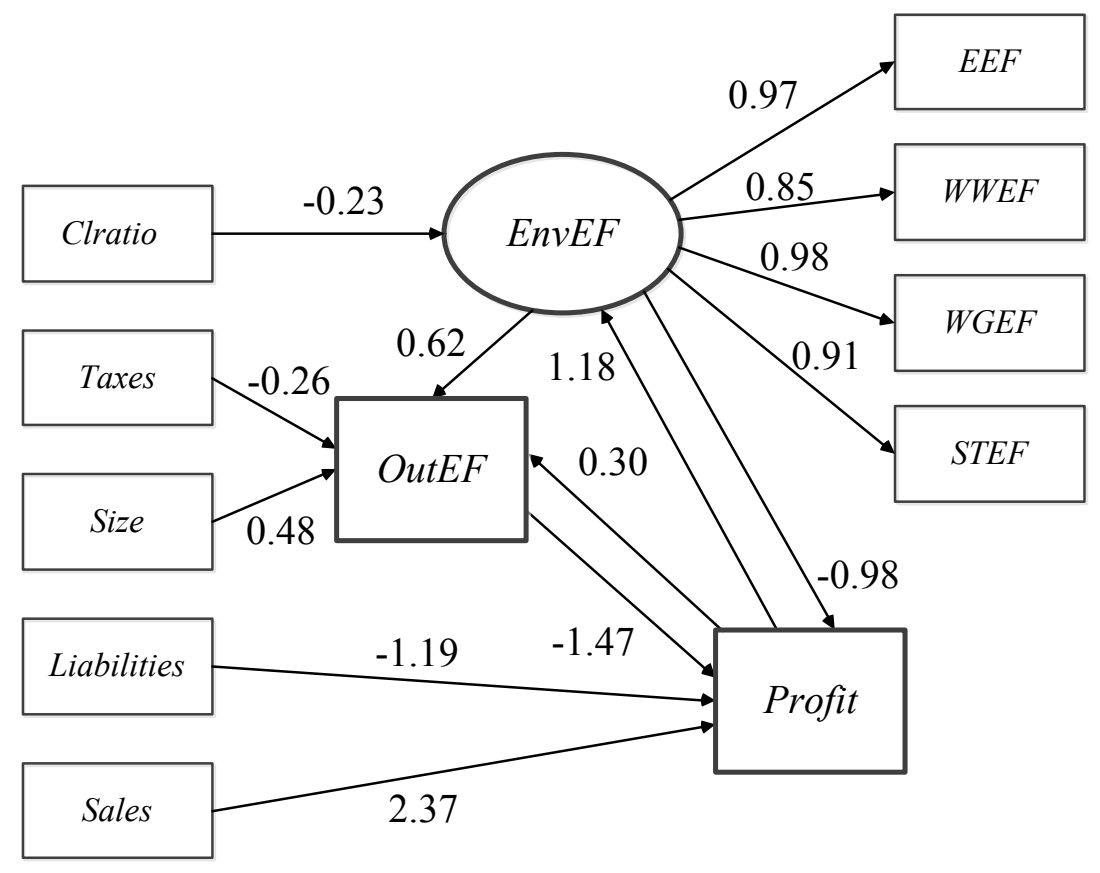

Fig 1. The path diagram

Note: The latent variable $E n v E F$ is in the ellips; observed varaibles are in rectangles; an arrow indicates a direct influence; measurement errors and structural errors have been omitted.

\section{Table 1}

Input and output variables of the GDEA

\begin{tabular}{lllcccc}
\hline Variable & Definition & Unit & Mean & S.D. & Min. & Max. \\
\hline Capital & Value of fixed assets & Million Yuan & 70.38 & 361.28 & 0.63 & 4170.39 \\
Labor & Number of employees & Capita & 514.25 & 1314.71 & 30.00 & 14300.00 \\
Energy & Coal consumption & Tons & 6775.10 & 16876.55 & 97.00 & 146515.00 \\
Water & Water use & Thousand Tons & 635.00 & 900.75 & 10.00 & 8724.47 \\
Output & Industrial output value & Million Yuan & 285.23 & 1389.36 & 6.70 & 16005.16 \\
Wastewater & Volume of waste water discharges & Thousand Tons & 480.78 & 690.57 & 0.80 & 6979.58 \\
Wastegas & Volume of waste gas emissions & Million Cubic meters & 70.00 & 169.68 & 1.20 & 1465.15 \\
Soot & Volume of soot emissions & Tons & 37.43 & 64.34 & 0.75 & 455.00 \\
\hline
\end{tabular}

Source: Environmental Protection Department of Jiangsu Province and Chinese Industrial Enterprises Database Note: S.D. denotes standard deviation, Min. minimum and Max. maximum.

Table 2

The SEM control variables

\begin{tabular}{|c|c|c|c|c|c|c|}
\hline variable & Definition & Unit & Mean & S.D. & Min. & Max. \\
\hline \multirow{2}{*}{ Clratio } & \multirow{2}{*}{ The ratio of capital to labor } & Million & 0.099 & 0.076 & 0.005 & 0.555 \\
\hline & & Yuan/capita & & & & \\
\hline Age & Age of the firm & Years & 15.956 & 11.369 & 5.000 & 54.000 \\
\hline Taxes & $\begin{array}{l}\text { The ratio of taxes and surcharge paid for } \\
\text { main operations to total profit }\end{array}$ & & 0.339 & 0.352 & 0.000 & 1.984 \\
\hline Size & Total assets & Billion Yuan & 0.193 & 0.952 & 0.003 & 11.035 \\
\hline Liabilities & Total liabilities & Million Yuan & 274.268 & 1361.187 & 7.186 & 15783.505 \\
\hline
\end{tabular}




\begin{tabular}{lllcccc} 
Sales & Gross industrial products sales & Million Yuan & 111.180 & 482.608 & 0.455 & 5538.57 \\
\multirow{2}{*}{ Profit } & The ratio of total profits to total sales in & & 0.327 & 0.060 & -0.253 & 0.297 \\
& 2008 & Million Yuan & & & & \\
\hline
\end{tabular}

Source: Chinese Industrial Enterprises Database

Note: S.D. denotes standard deviation, Min. minimum and Max. maximum.

\section{Table 3}

Descriptive statistics of the efficiency measures

\begin{tabular}{lccc}
\hline Efficiency measure & Mean & SD & Min \\
\hline Generalized/overall efficiency (GEF) & 0.2902 & 0.3416 & 0.0292 \\
Energy efficiency (EEF) & 0.3934 & 0.3391 & 0.0270 \\
WWEF (waste water efficiency) & 0.2896 & 0.3639 & 0.0124 \\
WGEF (waste gas efficiency) & 0.3832 & 0.3320 & 0.0185 \\
STEF (soot efficiency) & 0.3874 & 0.3606 & 0.0080 \\
Output efficiency $($ OutEF) & 0.8189 & 0.2688 & 0.1809 \\
\hline
\end{tabular}

\section{Table 4}

SEM goodness-of-fit statistics

\begin{tabular}{lcccccc}
\hline & $\chi^{2} / d f$ & RMSEA & GFI & AGFI & CFI & NFI \\
\hline Initial Model & 1.639 & 0.064 & 0.94 & 0.86 & 0.98 & 0.95 \\
Final Model & 1.806 & 0.073 & 0.93 & 0.86 & 0.98 & 0.96 \\
Cut off value & $<3$ & $<0.08$ & $>0.90$ & $>0.80$ & $>0.90$ & $>0.90$ \\
\hline
\end{tabular}

Note: For more details about cut off values see Hooper et al. (2008).

\section{Table 5}

Matrix of modification indices of the SEM

\begin{tabular}{lccc}
\hline & EnvEF & OutEF & Profit \\
\hline EnvEF & ---- & --- & --- \\
OutEF & 0.04 & --- & --- \\
Profit & --- & --- & --- \\
Clratio & --- & 0.00 & 0.08 \\
Age & & & \\
Taxes & 3.22 & --- & 0.42 \\
Size & 0.58 & --- & 0.68 \\
Liabilities & 2.48 & 0.15 & --- \\
Sales & 0.79 & 0.15 & --- \\
\hline
\end{tabular}

Note: critical value: 7

Table 6

The SEM measurement model

\begin{tabular}{lccc}
\hline Latent variable & Indicator & Coefficient & $\mathrm{R}^{2}$ \\
\hline EnvEF & $E E F$ & 0.33 & 0.94
\end{tabular}




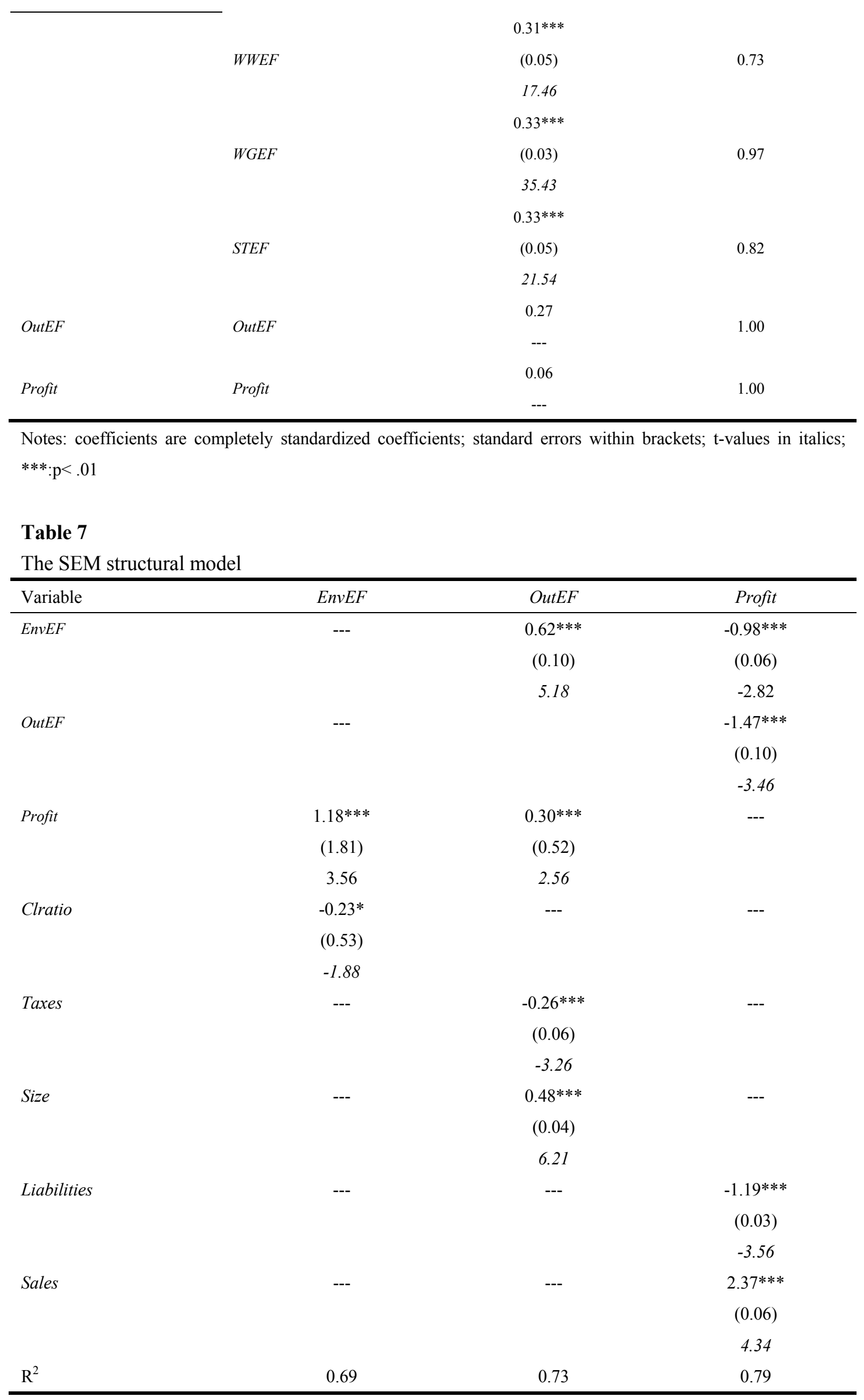


Notes: coefficients are completely standardized coefficients; standard errors within brackets; $t$-values in italics; $*: \mathrm{p}<.10, * *: \mathrm{p}<.05, * * *: \mathrm{p}<.01$.

\section{Table 8}

Standardized total effects of the SEM

\begin{tabular}{|c|c|c|c|}
\hline & $E n v E F$ & OutEF & Profit \\
\hline \multirow[t]{3}{*}{$E n v E F$} & $-0.61 * * *$ & $0.09 *$ & $-0.51 * * *$ \\
\hline & $(0.14)$ & $(0.04)$ & $(0.01)$ \\
\hline & -4.49 & 1.90 & -10.22 \\
\hline \multirow[t]{3}{*}{ OutEF } & $-0.47 * * *$ & $-0.41 * * *$ & $-0.40 * * *$ \\
\hline & (0.09) & $(0.10)$ & $(0.02)$ \\
\hline & -6.34 & -4.04 & -4.89 \\
\hline \multirow[t]{3}{*}{ Profit } & $0.32 * * *$ & $0.28 * * *$ & $-0.73 * * *$ \\
\hline & $(0.32)$ & $(0.23)$ & $(0.10)$ \\
\hline & 5.44 & 5.48 & -7.50 \\
\hline \multirow[t]{3}{*}{ Clratio } & -0.09 & -0.02 & $0.12 *$ \\
\hline & $(0.24)$ & $(0.05)$ & $(0.05)$ \\
\hline & -1.61 & -1.35 & 1.87 \\
\hline \multirow[t]{3}{*}{ Taxes } & $0.12 * * *$ & $-0.15^{* * *}$ & $0.10 * * *$ \\
\hline & $(0.04)$ & $(0.04)$ & $(0.01)$ \\
\hline & 2.86 & -3.04 & 2.67 \\
\hline \multirow[t]{3}{*}{ Size } & $-0.23 * * *$ & $0.28 * * *$ & $-0.19 * * *$ \\
\hline & $(0.03)$ & $(0.03)$ & $(0.01)$ \\
\hline & -4.41 & 4.02 & -3.98 \\
\hline \multirow[t]{3}{*}{ Liabilities } & $-0.38 * * *$ & $-0.33 * * *$ & $-0.32 * * *$ \\
\hline & $(0.06)$ & $(0.03)$ & $(0.01)$ \\
\hline & -3.74 & -4.75 & -3.61 \\
\hline \multirow[t]{3}{*}{ Sales } & $0.76^{* * *}$ & $0.67 * * *$ & $0.64 * * *$ \\
\hline & $(0.07)$ & $(0.05)$ & $(0.01)$ \\
\hline & 6.03 & 6.29 & 5.00 \\
\hline
\end{tabular}

Notes: standard errors within brackets; t-values in italics; ${ }^{*}: \mathrm{p}<.10,{ }^{* *}: \mathrm{p}<.05,{ }^{* * *}: \mathrm{p}<.01$. 